\title{
What and how are we sharing? A systematic review of the sharing paradigm and practices
}

\author{
Hyeonju Ryu ${ }^{1}$ (1) $\cdot$ Mrittika Basu $^{2} \cdot$ Osamu Saito $^{2}$
}

Received: 2 April 2018 / Accepted: 29 September 2018 / Published online: 26 October 2018

(c) Springer Japan KK, part of Springer Nature 2018

\begin{abstract}
Sharing of resources, goods, services, experiences and knowledge is one of the fundamental practices that has been widely embedded in human nature. With the advance of information and communication technology, the realm of sharing has expanded drastically, which has led to the evolution of the 'sharing paradigm'. In spite of the increasing attention on the new sharing phenomenon and its potential contribution to a sustainable and resilient society, there is a lack of comprehensive understanding of varied sharing practices in the context of sustainability and resilience. This study maps out the academic landscape of sharing studies and examines what and how we share by a systematic literature review. Based on the review of 297 peer-reviewed papers, we explore the features of varied sharing practices identified in academia. We also discuss research gaps in sharing paradigm studies and the potential contribution of sharing to building sustainable and resilient societies. Our results show regional and sectoral imbalances in the sharing studies. The findings also illustrate that sharing of manufactured goods and accommodations, and access-based sharing with monetary compensation via intermediaries such as online platforms are predominant. Our evaluation provides a bird's-eye view of existing sharing studies and practices, enabling the discovery of new opportunities for sustainable and resilient societies.
\end{abstract}

Keywords Sharing paradigm $\cdot$ Sharing economy $\cdot$ Collaborative consumption $\cdot$ Sustainability $\cdot$ Resilience

\section{Introduction}

Sharing is a fundamental part of human nature (McLaren and Agyeman 2015; Price 1975). Humans in early history shared food and materials with family members from hunting and collecting (Belk 2014). In the 21st century, the scope of sharing has expanded, driven by developments in information and communications technology (ICT) (Barnes and Mattsson 2016). We share not only food and goods with our family and close friends, but also experiences and knowledge with strangers via the internet. In the past few years,

Handled by Eiji Hosoda, Keio University, Japan.

Hyeonju Ryu

hyeonju.ryu@protonmail.com

1 Division of Global Forestry, Department of Forest Policy and Economics, National Institute of Forest Science, 57 Heogi-ro, Dongdaemun-gu, Seoul 02455, Republic of Korea

2 United Nations University Institute for the Advanced Study of Sustainability, 5-53-70 Jingumae, Shibuya, Tokayo 150-8925, Japan the concept of sharing evolved as a 'sharing economy'. The sharing economy is an 'economic model based on sharing assets among groups of people rather than owning them' (Ballus-Armet et al. 2014). A number of sharing economy initiatives have facilitated easier and broader connections among sharing partners. For example, Airbnb and Couchsurfing have accelerated global home sharing, and Uber and Car2Go mediate sharing of rides and cars. Freecycle and Fashion Libraries offer platforms for sharing second-hand goods, and Taskrabbit and Timebanks allow people to share their skills and time.

Though the traditional practice of sharing is longstanding, online platforms like Ebay, Craigslist, and Couchsurfing emerged during the late 1990s and early-mid 2000s that transformed sharing into business models. These platforms enabled individuals to develop peer to peer relationships through internet-mediated interactions that allowed individuals to access others' assets. The concept of sharing economy gained wider attention around 2011-2012 as it grew from not-for-profit initiatives like Freecycle and Craigslist to big business models like Uber and Airbnb (Martin 2016). Eventually, the concept of sharing economy diverged 
into multiple terms like 'collaborative consumption', 'access economy', and 'peer economy' (Dredge and Gyimóthy 2015; Pettersen 2017). According to Botsman and Rogers (2010), the term collaborative consumption includes not only traditional sharing, bartering, lending, renting, gifting and swapping, but also new forms of these practices through technology and peer communities. Access economy emphasizes the transition from property regimes to access regimes under which things can be accessed without owning them individually (Kassan and Orsi 2012; Rifkin 2001). Peer economy can also be called 'peer to peer marketplaces (economy)', which enable people to monetize goods, assets and skills within their possession through online marketplaces (Cheng 2014).

To explain the varied concepts of sharing, McLaren and Agyeman (2015) proposed an umbrella term: the 'sharing paradigm'. The sharing paradigm embraces a broader range of activities beyond the concept of sharing economy including sharing of goods, services, and experiences between individuals and within collectives and the public (McLaren and Agyeman 2015). They classified diverse terms in the sharing paradigm into four quadrants using two axes of contrasting features: from intermediated sharing to sociocultural (informal) sharing and from communal sharing to commercial sharing (Fig. 1). The sharing paradigm can offer a framework for a holistic understanding of the sharing phenomenon. There is, however, a lack of studies that examine a wide range of sharing practices under this framework.

The sharing phenomenon has often been explained in the context of sustainability. Many studies suggest that the global movement towards sustainable consumption fueled the sharing economy along with the advent of the internet
(Albinsson and Perera 2012; Barnes and Mattsson 2016). Sharing and collaborative consumption allows enjoyment of products with low or no cost of ownership and reduces waste from excessive production and consumption (Akbar et al. 2016; Retamal 2017). For example, car sharing can contribute to reducing the total number of cars owned by individuals and increasing car use efficiency, hence reducing the environmental impacts of car production. Although 'sustainability' frequently occurs in the discourse of sharing economy, sharing has been overlooked in sustainable development dialogs. Among 17 Sustainable Development Goals (SDGs) and 169 targets, sharing has been captured by a limited number of goals such as Goal 2 , Target $2.5^{\prime} \ldots$ promote access to and fair and equitable sharing of benefits arising from the utilization of genetic resources and associated traditional knowledge, as internationally agreed' (UN General Assembly 2015). Knowledge sharing is also referred to in Goal 17 to enhance international cooperation and partnership for sustainable development (17.16). In contrast to inclusiveness and resilience, which are frequently used throughout the 2030 Agenda for Sustainable Development, sharing is not fully incorporated into the international discourse of sustainable development.

Despite the emergence of the sharing paradigm and its potential contribution to sustainable and resilient societies, there is a lack of holistic understanding of sharing studies and various forms of sharing practices in the context of sustainability and resilience science. Therefore, this paper attempts to provide a comprehensive understanding of the academic landscape of sharing studies in relation to sustainability and resilience by the sharing paradigm framework
Fig. 1 The sharing paradigm Adapted from McLaren and Agyeman (2015)

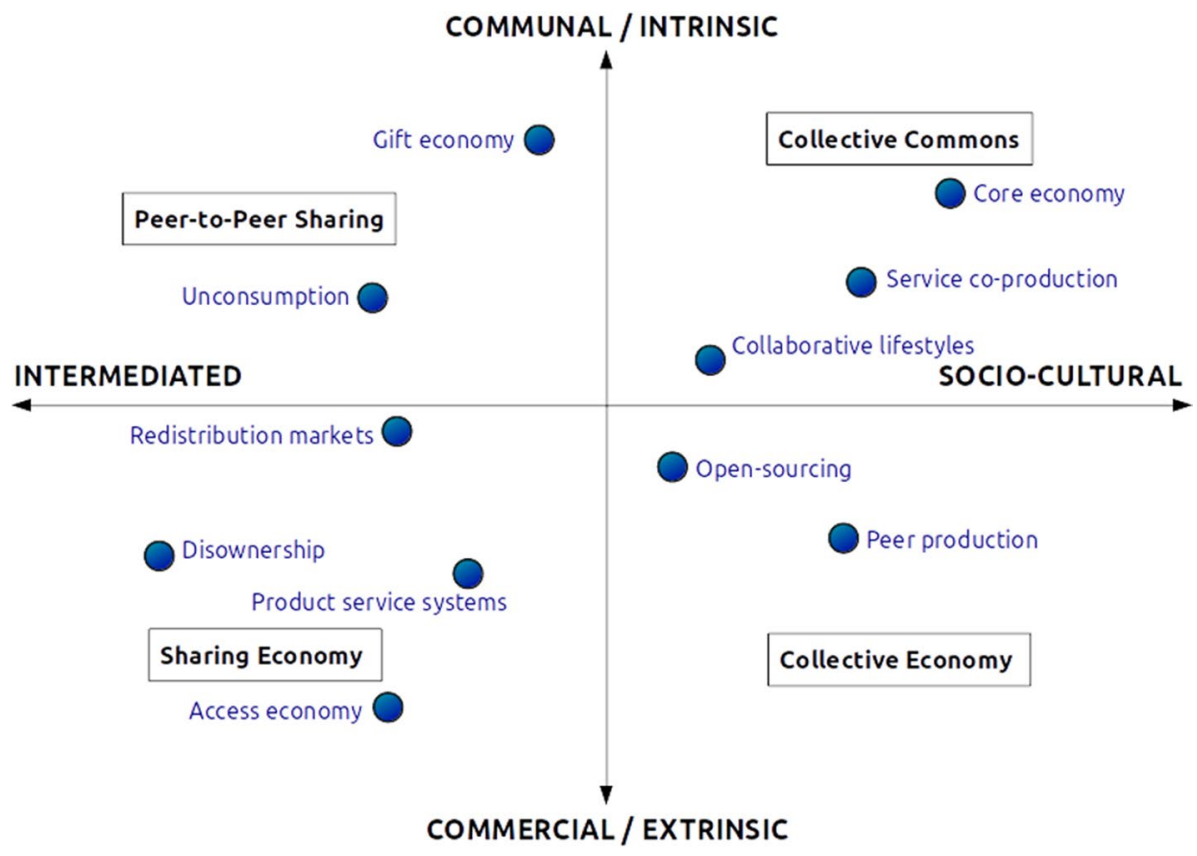


suggested by McLaren and Agyeman (2015). The analysis outlines what and how we share based on a systematic review of the latest research on the sharing paradigm. In this review, we (1) examine the research trend on the key concepts in the sharing paradigm, (2) analyze the temporal change and geographical distribution of sharing studies, (3) explore features of sharing practices in the literature through a content analysis, and (4) discuss research gaps and opportunities to build a more sustainable and resilient society.

\section{Methodology}

To describe the academic landscape of sharing paradigm research, we retrieved and collected peer-reviewed scientific papers. Figure 2 illustrates the step-by-step methodological approach followed in this study. We searched papers on each key term in the sharing paradigm framework using Scopus and analyzed the research trend (Step 1, Fig. 2). Since expansion of sharing economy is relatively recent, we

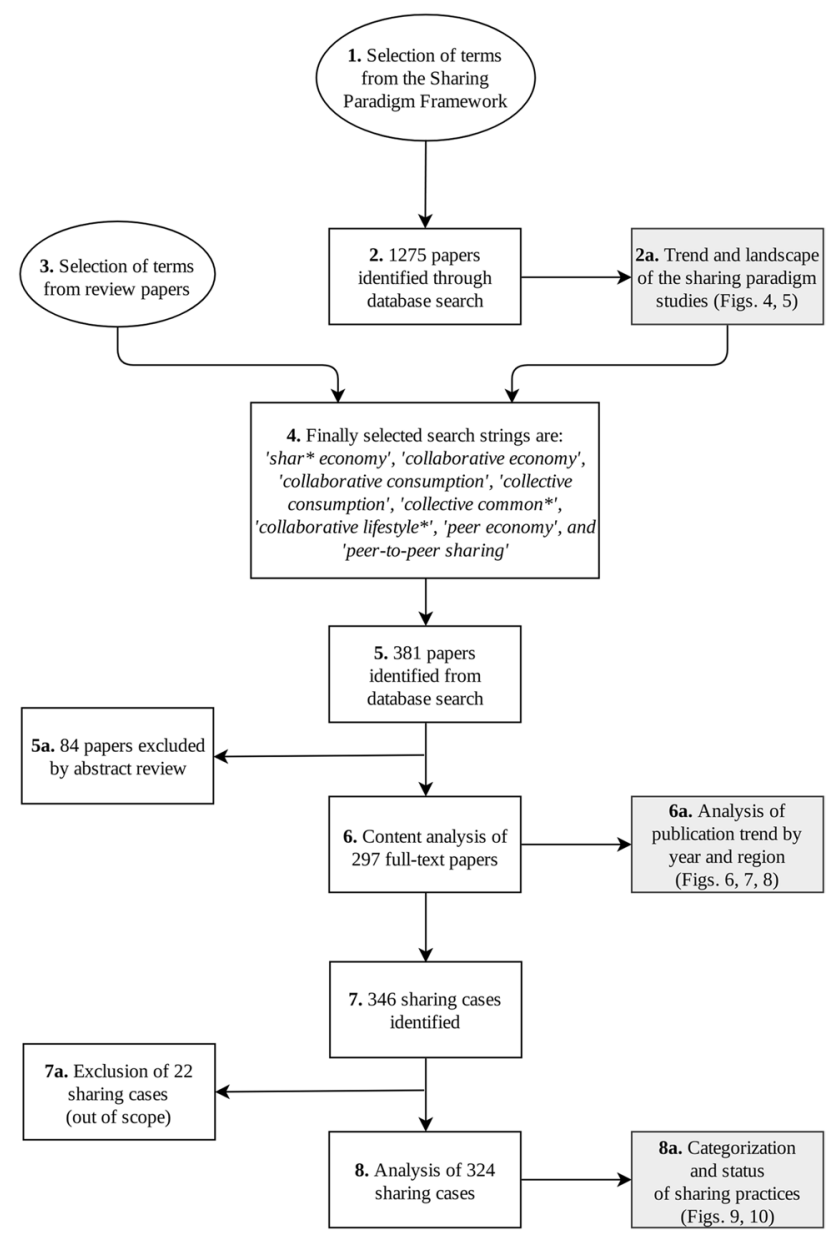

Fig. 2 Flow diagram of the review strategy. Gray boxes refer to results focused on peer-reviewed journal articles and review papers published in the last ten years between 2008 and 2017, and written in English. Within the search options of title, abstract and keywords, each of the 15 terms used in the sharing paradigm (e.g., 'gift economy', 'peer-to-peer sharing', 'collective common') (Fig. 1) was used as input. A total of 1,275 papers were retrieved excluding duplicated articles (Step 2, Fig. 2). We quantified the volume of papers by term (e.g., 'gift economy', 'peer-to-peer sharing', 'collective common' in Fig. 1) and analyzed the research trend over the past ten years (Step 2a, Fig. 2).

Due to the magnificent amount of publications, we narrowed down the scope to studies that follow the definition of sharing by Belk (2007): 'the act and process of distributing what is ours to others for their use as well as the act and process of receiving something from others for our use'. Based on this definition, the scope of the analysis is limited to distribution of goods and services. Collaborative production (e.g., peer production) was excluded as it is classified as a shared activity that involves no allocation of resources. Sharing of digital files such as music and photos was also excluded for its distinctive features from materials and services (John 2013). Next, search words were carefully extracted from review papers (e.g., Bradley and Pargman 2017; Cheng 2016; Pettersen 2017) and from the proposed framework of the sharing paradigm by McLaren and Agyeman (2015) (Step 3, Fig. 2). To select the search strings, the academic landscape of the sharing paradigm was considered based on the initial review of 1,275 number of papers. The results were later updated with a complete set of papers from 2017 by repeating the search in January 2018. The key words include 'shar* economy', 'collaborative economy', 'collaborative consumption', 'collective consumption', 'collective commons', 'collaborative lifestyle*', 'peer economy', and 'peer-to-peer sharing' for title, abstract and keywords (Step 4, Fig. 2). In the initial search, 381 papers appeared, among which 84 papers were excluded due to unmatched format, scope, language, or keywords and papers where the sharing economy was not the main topic (Step 5 and 5a, Fig. 2). After the screening, 297 papers were selected for a content analysis (Step 6, Fig. 2). Among the selected papers, the articles with "sustainable" or "sustainability" and with "resilient" or "resilience" in their titles, abstracts or keywords were quantified and reviewed. We also examined the publication trend by year and region (Step 6a, Fig. 2).

The full texts of the selected papers were reviewed, and 346 cases of sharing practices were identified (Step 7, Fig. 2). For the analysis, we further excluded 22 cases on professional services including repairs and medical services provided by qualified workers (e.g., Fix Forward) and online banking (e.g., M-Pesa) due to irrelevance to the research scope (Step 7a, Fig. 2). 
For the content analysis of 324 sharing cases, we categorized shared goods and services by sector including agriculture, education services, energy services, finance, manufactured goods, personal services, real estate, and transportation services (Step 8 and 8a, Fig. 2). The categories were adapted from the Standard Industrial Classification (SIC), a widely used classification system (Phillips and Ormsby 2016). Since sectoral categorization of sharing has not been established, we used the SIC to capture a wide range of sharing practices.

We also identified traits of the sharing practices such as profit orientation, ownership transfer, tangibility, scale and existence of intermediary. We defined 'profit orientation' as the existence of monetary benefits to the provider. For example, Uber and Airbnb were categorized as 'forprofit', since the providers of ride or accommodation services receive payment from the recipients for the service. 'Not-for-profit' sharing cases include carpooling and the exchange of 'nights' or 'time' as payment as well as sharing without any compensation. 'Ownership transfer' refers to whether the ownership of a shared thing has transferred from the provider to recipient or not. Cases with ownership transfer include selling or giving second-hand goods, while lending tools and renting vehicles are sharing without ownership transfer. 'Tangibility' divides cases into sharing of materials (tangible) and sharing of services (intangible). The 'scale' denotes the geographical scope of sharing such as local, national, regional and global. The 'existence of an intermediary' denotes whether there is an intermediary such as an online platform or organization that connects providers and recipients in sharing.

Based on the profit orientation and ownership transfer, sharing activities were divided into six types: 'Selling', 'Gifting', 'Renting', 'Lending', 'Servicing', and
'Volunteering,' using the categorization provided by Chasin et al. (2017) (Fig. 3). Gifting and selling are provisions of a physical object, but selling involves payment while giving is for free. Lending and renting give access to tangible resources for no profit and profit, respectively. Volunteering is the provision of intangible resources for free, while servicing requires compensation for such provision.

\section{Results}

\section{Academic landscape of the sharing paradigm}

In total, 1,275 peer-reviewed articles on the sharing paradigm were published between 2008 and 2017. These papers may also include some irrelevant studies. For example, search of 'disownership' included disownership in the context of mental health. It is also likely that the results miss out on papers that do not explicitly use our search terms. However, it gives a quick overview of the publication trend. The number of publications on the sharing paradigm has increased by nine times over the last decade. They show a steep increase since 2014, mainly due to the rise in the number of studies on the sharing economy (Fig. 4). The landscape of the sharing paradigm studies is illustrated in Fig. 5, where the size of bubbles represents the number of publications from 2008 to 2017 (See Appendix 1 for the figures). Within the sharing paradigm, majority of the studies dealt with commercial and intermediated sharing as in the bottom-left quadrant of the framework (Fig. 5). The most studied topic was the 'product service system' (38\%)-a system where 'the customer pays for using an asset, rather than for its purchase' (Retamal 2017), followed by 'sharing
Fig. 3 Types of sharing by the level of commercialization and reliance on ownership

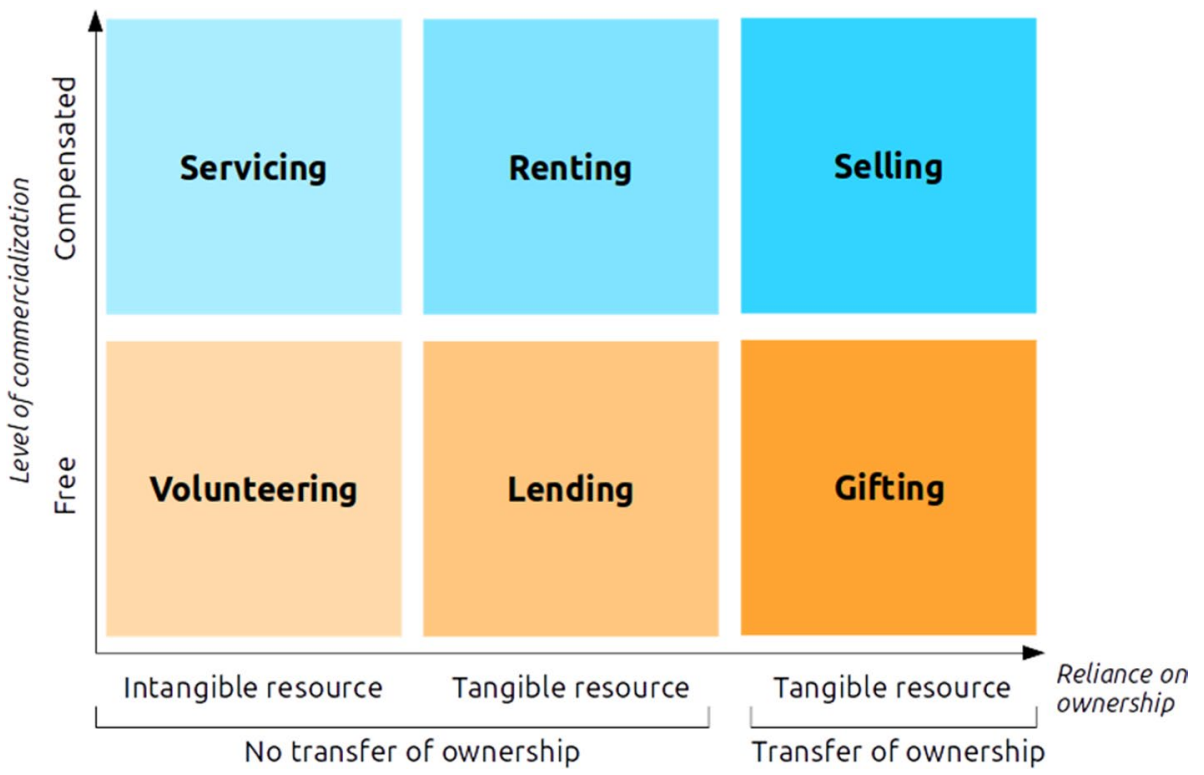




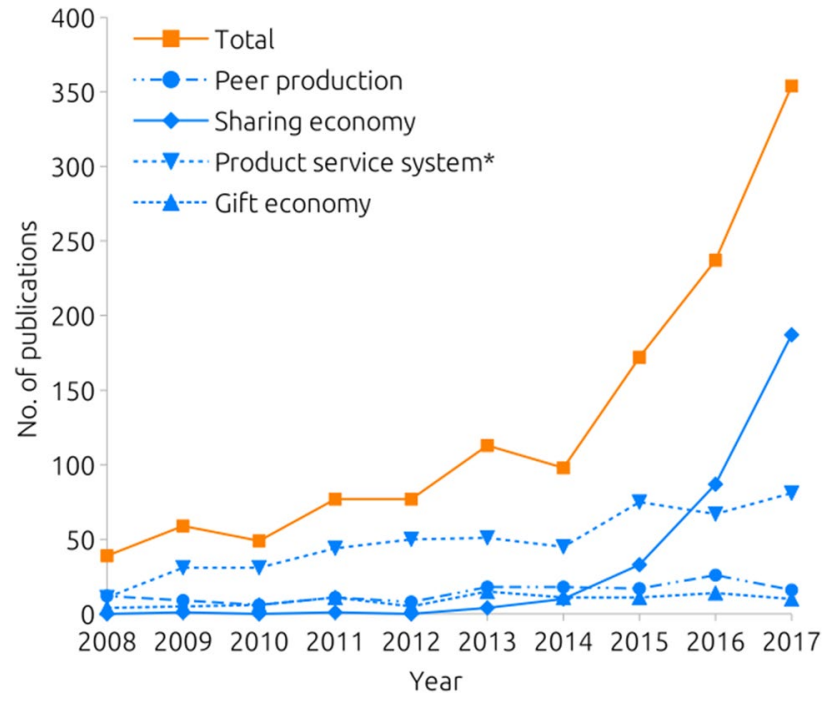

Fig. 4 Research trends in the sharing paradigm. The graph shows the volume of all retrieved publications $(n=1275)$ and four terms in the sharing paradigm that returned the most results (product service system, sharing economy, peer production and gift economy). Each keyword was searched in Scopus

economy' (25\%), 'peer production' (11\%), and 'gift economy' $(7 \%)$.

Among the 297 papers reviewed for the content analysis, $19 \%(n=57)$ contained 'sustainable' or 'sustainability' in the title, abstract or keywords. The number of studies that linked sharing with sustainability increased rapidly since 2014 , from two papers in 2014 to 22 papers in 2017 (Fig. 6). This can be partly associated with growing attention to the Sustainable Development Goals (SDGs) adopted in 2015 by the United Nations General Assembly (2015). The studies discussed sustainability aspects of sharing in terms of sharers' attitudes towards sustainability (Akbar et al. 2016; Barnes and Mattsson 2016; Hamari et al. 2016; Roos and Hahn 2017); environmental impacts-including efficiency in resource use, and greenhouse gas emissions (Ala-Mantila et al. 2016; Berners-Lee 2011; Lahti and Selosmaa 2013); contribution to social capital (Albinsson and Perera 2012; Aptekar 2016; Tussyadiah 2016); and change towards sustainable consumption (Ala-Mantila et al. 2016). As for resilience, only three papers mentioned 'resilience' in their title, abstract, or keywords, of which two studies discussed contribution of sharing to socio-environmental resilience (Cellucci and Sivo 2017; Heylighen 2017) while the other used the term 'resilience' as 'stability' of an internet communication system. A single study among the reviewed literature discussed sharing paradigm in both sustainability and resilience perspectives in depth. Heylighen (2017) explains that optimized matching of offers and demands in a sharing economy can tackle both sustainability and resilience issues in principle. The author argues that an on-demand economy helps in achieving a sustainable society by preventing excessive production. Also, such an economic system has a potential to provide sufficient and diverse offers and to enable accurate monitoring of flows for a quick remedy, which contributes to resilience according to him.

Geographically, majority of study sites is located in Europe, followed by global studies and North America (mostly the United States) (Figs. 7, 8). Sharing practices
Fig. 5 The academic landscape of the sharing paradigm studies. The size of the bubbles indicates the number of publications. Diagram adapted from McLaren and Agyeman (2015)

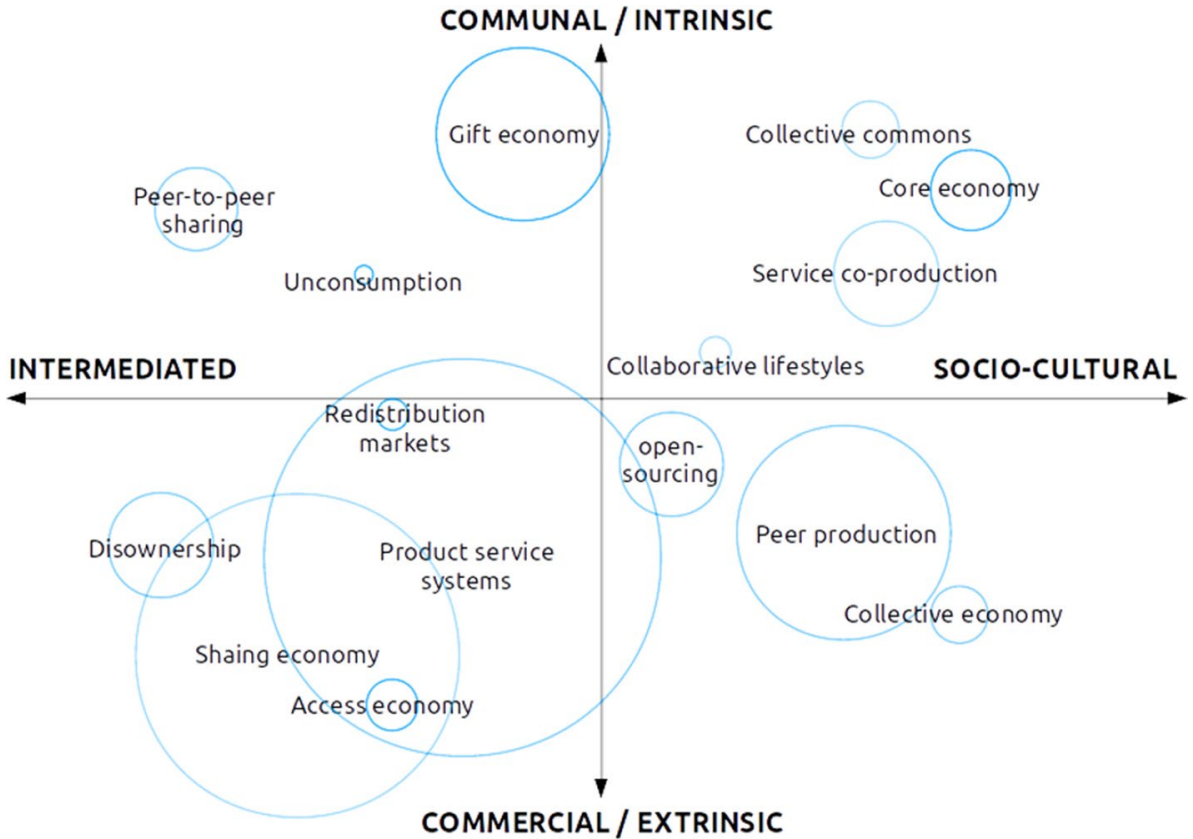


in Asian countries such as Taiwan, China, and South Korea started to draw attention in 2016, yet the number of studies remained low. Few studies were carried out in Africa and South America (Fig. 7). In addition, 21\% of the reviewed papers were not associated with any specific countries or regions.

\section{What and how are we sharing?}

The content analysis examines what has been shared and how it has been shared. Sharing of manufactured goods including vehicles, clothes, machines and tools was predominent in the literature (Fig. 9, Appendix 2). Among the manufactured goods, various forms of car-sharing were

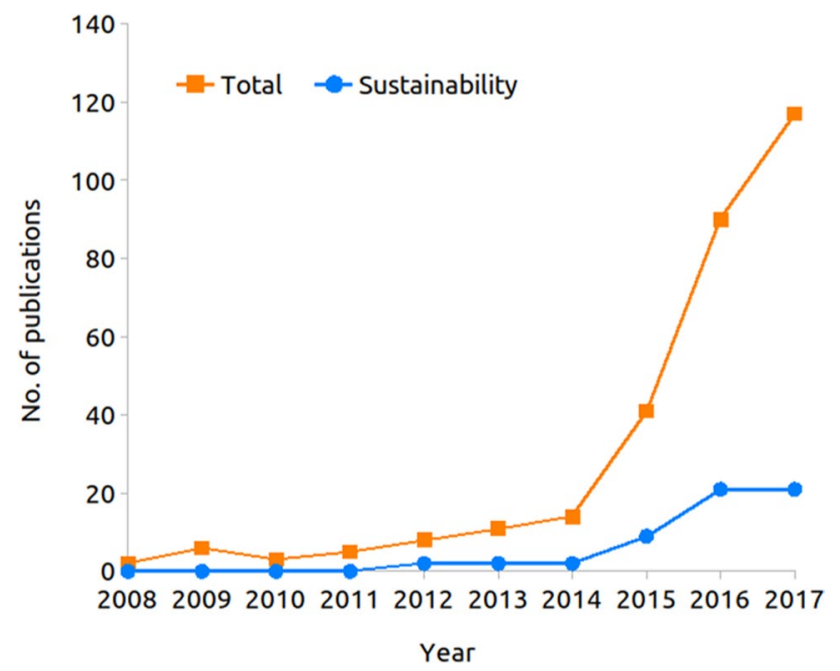

Fig. 6 Publication trend in the sharing paradigm studies linked with sustainability between 2008 and $2017(n=297)$ explored, which include rental services by private companies (e.g., Car2Go, Zipcar) and by manufacturers (product service systems), peer-to-peer (P2P) car sharing (e.g., BuzzCar, Drivy, GoCar), and collective ownership in communities (e.g., car sharing in ecovillages). Examples of other shared goods include gifting baby equipment to community members (c.f. Lampinen et al. 2015); borrowing clothes from fashion libraries (c.f. Pedersen and Netter 2015); re-selling used goods; using a neighbor's washing machine (e.g., La machine du voisin); and sharing 3D printers at collaborative labs (e.g., Fab Lab).

Real estate such as accommodations, work spaces, farmlands, warehouses and parking lots were also investigated in many studies. Studies on space sharing mainly dealt with P2P home sharing, both for profit (e.g., Airbnb, HomeAway) and non-profit (e.g., Couchsurfing, GuestToGuest, BeWelcome). Co-housing cases were also shown in a few studies (c.f. Huber 2017; Luckner et al. 2015). Besides accommodations, the space sharing cases included sharing of urban gardens and yards for farming (e.g., Landshare and Plantez Chez Nous) and work places (e.g., Hoffice and Fab Lab).

Some studies focused on sharing of transportation services such as carpooling and mobility services (e.g., Uber, Lyft). Most of the transportation sharing studies were on ride-sharing services by Uber, and a few studies examined P2P carpooling (e.g. BlablaCar, taxi ridesharing, RideIT). The emergence of Transportation Network Companies (TNCs) was also discussed in several studies (Pfeffer-Gillett 2016; Shaheen and Chan 2016; Wahyuningtyas 2016).

Cases of sharing personal services included childcare, dog care, home improvement, cleaning, gardening, repairs, and cooking. Most of the personal service cases were intermediated by a third party. For example, Taskrabbit provides an online platform for matching errand requests
Fig. 7 The number of publications on sharing paradigm by continent

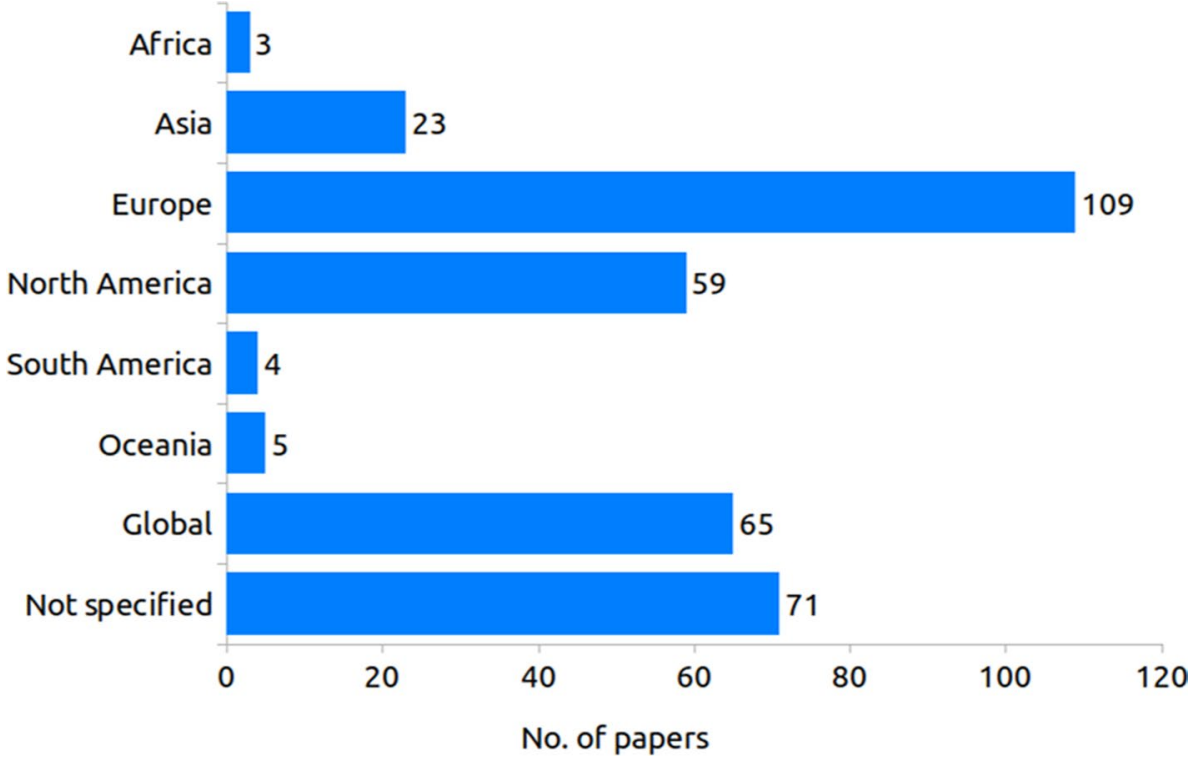




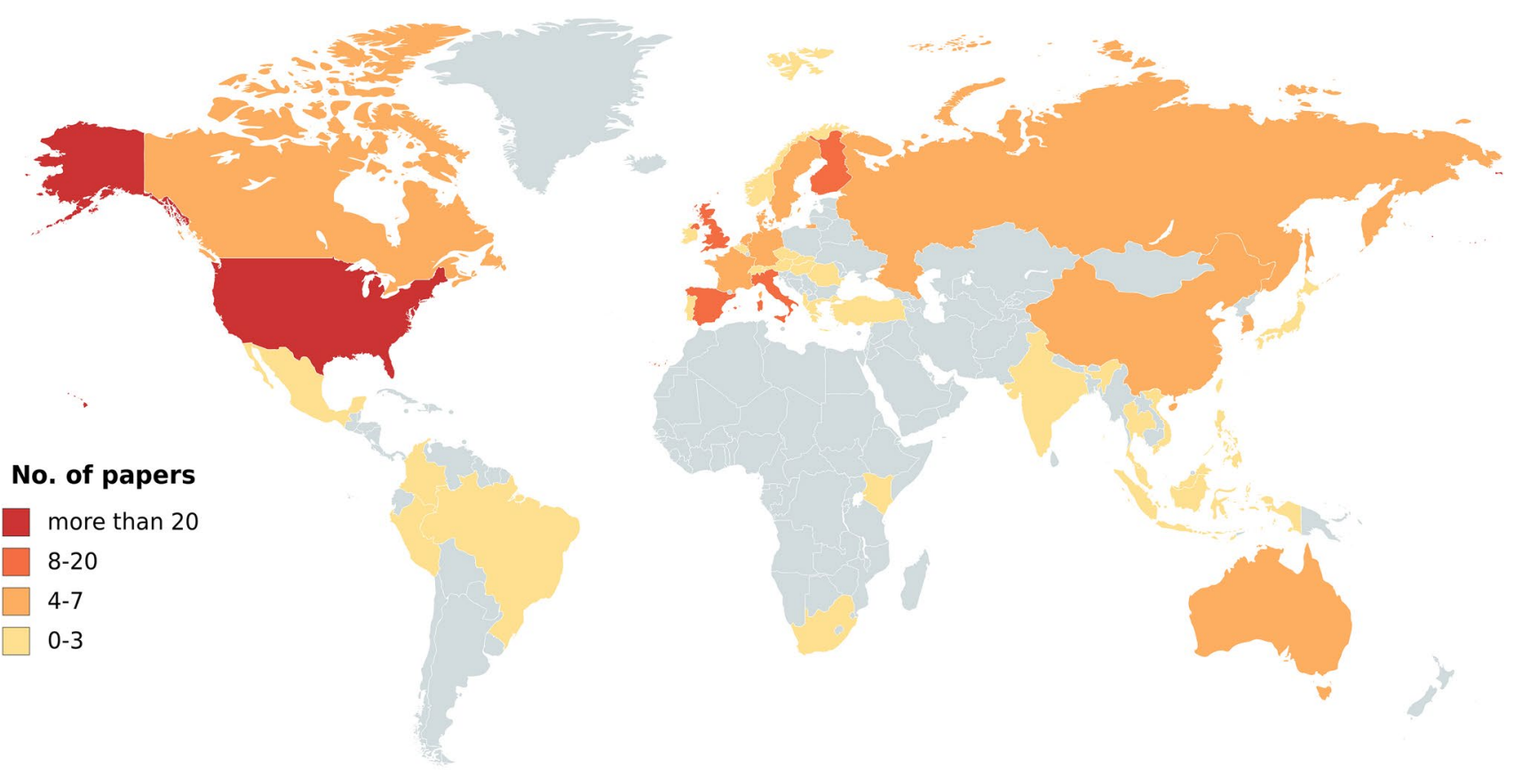

Fig. 8 The number of sharing paradigm studies by country. The papers on the global or regional cases are not presented on the map

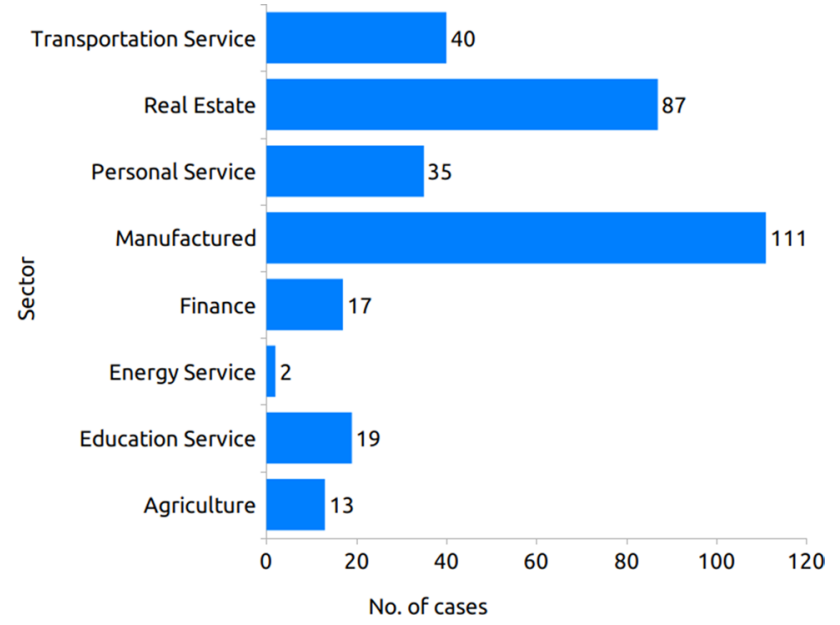

Fig. 9 Goods and services we are sharing: the number of sharing cases by industrial sector $(n=324)$

(e.g., moving, furniture assembly, yard work, home repair and cleaning) and available laborers (Ravenelle 2017; Schor 2017; Thebault-Spieker et al. 2017). Another example is Timebank through which people do others' chores and earn 'hours' as an exchange unit (Laamanen et al. 2015; Luckner et al. 2015). A few studies examined cooking services (e.g., Kitchensurfing, Food Swap) and bike repair (e.g., Bike Kitchen).
A limited number of studies investigated the rest of the sectors such as agriculture, finance, education services, and energy sharing (Fig. 9). Sharing practices in the agriculture sector were mainly gifting or swapping homegarden products via social events or online platforms (e.g., Landshare, Food Swap). In the finance sector, some cases of money lending services (e.g., Babyloan, Kiva) and crowdfunding (e.g., Arboribus, Patchwork Present) were studied in the context of the sharing paradigm (Balnaves 2012; Langley and Leyshon 2017). Cases in the education services sector include training (e.g., online courses), voluntary knowledge sharing (e.g. Wikipedia), and information sharing within communities (e.g., Single Parents' Network). Two energy service cases - heat and electricity prosumers-were also discussed in relation to the sharing paradigm (Bruggeman and Dehaene 2017; Butenko 2016).

The studies tended to focus on sharing via intermediaries, mainly by online platforms (Fig. 10). The number of commercialized sharing cases was larger than the number of communal sharing cases (gifting, lending, volunteering, and co-ownership). Most of the cases were 'renting', whereby the providers offer tangible materials (e.g., apartment, vehicles, etc.) to the recipients for monetary compensation. The co-ownership cases were co-housing practices. The scale of socio-cultural sharing was limited to the local level whereas the intermediated sharing varied in scale. Most of the gifting cases (32\%) were intermediated at the local scale, while many of the lending cases (46\%) were intermediated at the 
Fig. 10 Overview of sharing practices identified in the literature $(n=324)$. The thickness of the lines indicates the number of cases, which are given in the parentheses

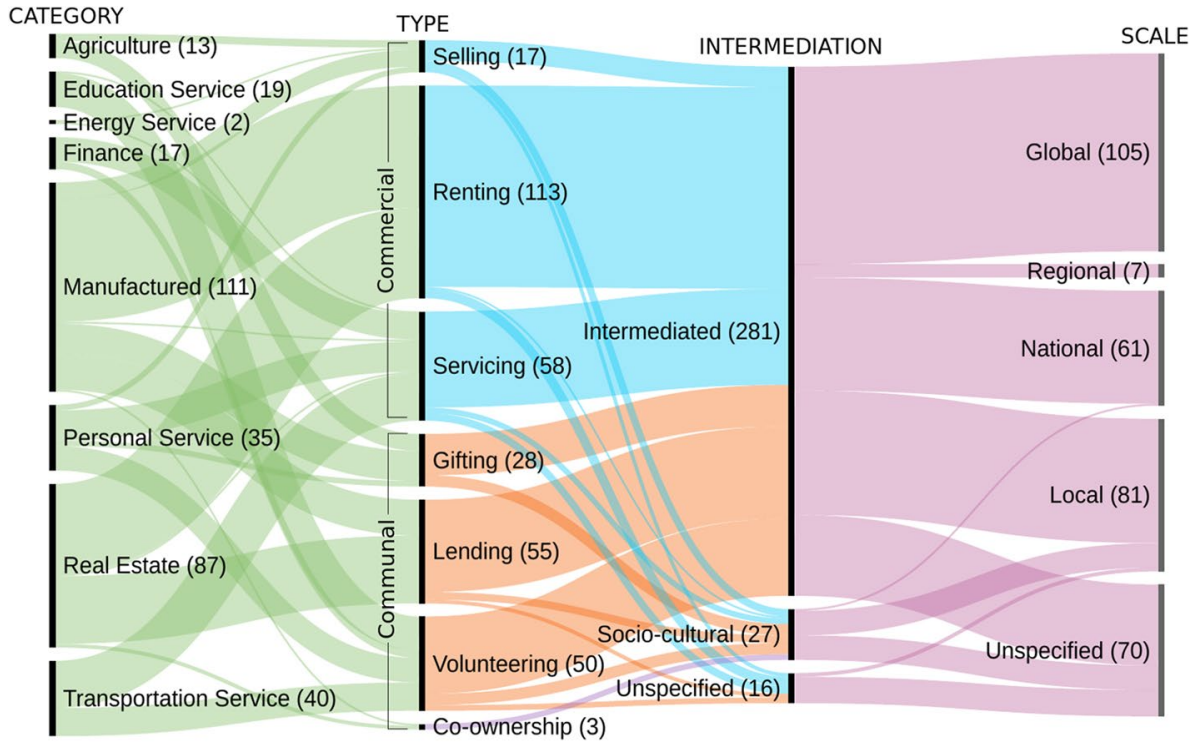

global scale (mostly accommodation such as Couchsurfing and HomeExchange).

\section{Discussion}

\section{Sharing in the literature: Research trend and gaps}

Through the extensive review of sharing paradigm studies, we examined the research trend in sharing studies and explored cases of sharing practices. We found that studies on the sharing paradigm increased significantly since 2014, mainly due to the increased research in the sharing economy. Even though the discourse on the new sharing phenomenon started in 2007 by Belk (2007), researchers-especially management researchers-paid little attention to the sharing economy, as sharing was often perceived as gift exchanges and in-home activities (Belk 2010). However, with the success of Airbnb and Uber, the concept of the sharing economy spread among the public via media in 2011 and 2012 (Martin 2016). In fact, the number of sharing economy platforms also increased by 2.5 times between 2010 and 2014 (Chasin et al. 2017), which reflects the increased attention on the sharing economy.

The systematic review revealed that a substantial number of studies investigated commercial, intermediated, and access-based sharing practices-mostly sharing of accommodation (Airbnb) and vehicles (Uber). The findings uncovered that most studies on the sharing paradigm focused on sharing practices with monetary compensation. Business aspects of sharing was one of the three research foci of the sharing economy studies (the other two include "nature of sharing economy' and 'sustainable development') (Cheng 2016), which is also the largest part of sharing paradigm studies. The large volume of studies on commercial sharing seems to reflect the growth of for-profit sharing activities. Chasin et al. (2017) showed in their review of internetbased sharing that $88 \%$ of online platforms mediated commercial sharing practices (Chasin et al. 2017), which may indicate that commercial sharing is dominant in the current sharing phenomenon. Many 'sharers' also responded that they participate in sharing mainly for economic benefits rather than environmental concerns or social caring (Barnes and Mattsson 2016; Buczynski 2013). Furthermore, more and more online platforms tend to focus on the economic benefits of sharing in their advertisements rather than on social and environmental sustainability over time (Chasin et al. 2017).

Many scholars have warned of the possible negative consequences of commercialization of sharing (Belk 2014; McLaren and Agyeman 2015). Sharing derived by commercial interests is likely to casualize labor, leaving the workers in the sharing economy without protection (Donini et al. 2017; McLaren and Agyeman 2015; Todolí-Signes 2017). Despite the issues, commercial sharing is an important part of the sharing paradigm regarding sustainability. Sharing and collective consumption allows effective use of resources, posing less pressure on the environment. For example, car sharing reduces the carbon footprint of manufacturing and increases frequency of usage (Fellows and Pitfield 2000). In the urban context, sharing food and goods among single dwellers can reduce food waste and carbon emissions and extend the lifespan of goods via second-hand markets (AlaMantila et al. 2016; Berners-Lee 2011; Novel 2014). A shift away from standard ownership models to sharing models has a significant potential to alter the relationship between producer and consumer, while there is a concern that resource consumption continues to grow rapidly in some areas. For 
example, personal electronic devices play a key role in the sharing economy, and at the same time, they require increasing volumes of metals and minerals to produce and energy to operate (Preston 2012). These examples suggest that we need to continuously examine and monitor both positive and negative impacts of shifting to sharing models on circular economy.

Commercial sharing practices also contribute to social cohesion. Commercial sharers often have multiple motivations for sharing - a combination of social engagement and sustainability as well as economic gains (Bucher et al. 2016; Chasin et al. 2017; Hamari et al. 2016). Tussyadiah (2015) described interacting with local people as an important driver of participation in accommodation sharing. A survey in the United States also showed that sharing economy is widely perceived to strengthen bonds of community (PwC 2015). Sharing for profit can also be linked with socioeconomic resilience. Manyika et al. (2016) argued that the market of shared workforce could buffer unemployment. Therefore, this increasing body of sharing, including commercial sharing, needs to be carefully understood to ensure how sharing economy and collaborative consumption contributes to sustainable societies.

Our results also show that only a few types of goods and services have been studied. In the past few years, the range of goods and services being shared has expanded dramatically (Chasin et al. 2017), from homes and cars to farmlands, food, pets, and knowledge. However, the majority of the studies examined only a few types of resources such as accommodation and vehicles. There are two possible drivers of the predominance of accommodation and vehicle sharing. First, researchers were influenced by the two significant business cases, accommodation (Airbnb) and vehicle (Uber). Since the success of Airbnb and Uber, many researchers have attempted to explain the new sharing business model and have examined participants' behaviors and the impacts of the businesses using those two well-known cases. Second, accommodation and vehicles are the resources being shared the most, at least in online sharing. Chasin et al. (2017) shows that accommodation was the most popular resource shared in $\mathrm{P} 2 \mathrm{P}$ platforms, followed by vehicle sharing, which in sum account for more than 90 percent of the platforms. However, more varied things are shared, especially in communal sharing. Boyko et al. (2017) identified 41 sharing cases (mostly communal sharing) taking place in cities, which include food, farm plants, chickens, gardens, journeys, and libraries. Sharing of workforce (or services) is another significant sector in the sharing paradigm, which needs more attention. A survey in the US and some European countries showed that about $25 \%$ of the working-age population make money by offering their labor as independent workers while only $4-6 \%$ are engaged in selling secondhand goods or leasing assets (Manyika et al. 2016). Hence, the present study emphasizes on the need of further studies on under-represented sharing practices in order to develop a clearer notion of sharing paradigm and its role in sustainability and resilience.

Further, an unbalanced distribution of sharing studies across the world was noticed. Most of the studies examined sharing activities in Europe and North America, and little attention was paid to sharing in developing countries such as Africa, Asia, and South America. A review of sharing economy studies by Cheng (2016) also addressed that the sharing economy has been explored predominantly from Western perspectives despite the rapid growth of sharing economies in the rest of the world (e.g., sharing in the Asia-Pacific region in Tolkach et al. 2016). This tendency in regional distribution of studies follows the distribution pattern of the origin countries of online sharing platforms (Chasin 2017). Sharing may differ by cultures, with different social norms and motivations to share (Albinsson and Perera 2009; McLaren and Agyeman 2015; Wittel 2011). Chasin et al. (2017) argued that the definition of sharing varies in different social contexts. Plieninger et al. (2018) show distinct distribution patterns and motivations of food sharing between Europe and Japan associated with different social challenges. Ince (2015) described how countries respond differently to two global sharing businessesAirbnb and Uber-in the case of Singapore and Australia. Only few sharing studies in Asia was reported in our study. However, fewer publication of peer-reviewed studies do not necessarily represent less sharing practices in Asia as well as Africa. Traditional communal sharing practices in Asia and Africa have been reported by several studies such as Landreth and Saito (2014), Saito et al. (2015; 2018), Kamiyama et al. (2016), and Boafo et al. (2016). As our search was limited to English language articles, it is likely to be linked to such a regional bias. The results clearly show that little is known about sharing practices in non-Western cultures by the international academic societies. Further studies need to be implemented to cover varied forms of sharing in different cultural contexts of under-investigated countries and regions.

\section{Sharing, sustainability, and resilience}

The present study shed a light on the research gap in sustainability and resilience aspects of sharing. A sharing economy and collaborative consumption is often seen as a means of achieving sustainable development (Ala-Mantila et al. 2016; Albinsson and Perera 2012; Martin 2016). Moreover, sharing has been identified as one of the key research agendas or opportunities for sustainability science (Takeuchi et al. 2017). Only a few papers, however, provided evidence of the direct and indirect impacts of 
sharing on building sustainable societies. Resilience is one of the cross-cutting and emphasized concepts frequently addressed in sustainable development. The term 'resilience' originated from the technical area of mechanical and engineering sciences, where it describes the properties of materials and their ability to withstand severe conditions (Hollnagel et al. 2006). The Intergovernmental Panel on Climate Change (IPCC 2014) defined resilience as 'the capacity of ... systems to cope with a hazardous event or trend or disturbance, responding or reorganizing in ways that maintain their essential function, identity, and structure, while also maintaining the capacity for adaptation, learning, and transformation'. Resilience is a distinctive concept from sustainability. While sustainability seeks a 'fail-safe' system, resilience can be described as a 'safe to fail' system (Ahern 2011). The literature survey by $\mathrm{Xu}$ et al. (2015) demonstrates the increased importance of resilience and its integration into the interdisciplinary area of sustainability studies. Achieving resilience aims to meet the socio-economic demands on resources for wellbeing by providing enough resources, whereas reaching sustainability involves maintaining the stocks of capitals at or above the threshold for well-being (Xu et al. 2015). As both sustainability and resilience are the core elements for human well-being, it is important to understand the sharing paradigm from both perspectives. Our review showed an increasing number of studies focus on sustainability issues in the context of sharing paradigm, yet few of them provide evidence. Moreover, no empirical studies have been conducted on the impact of sharing on resilience.

Having multiple sharing networks and platforms can contribute to enhancing resilience by ensuring redundancy and diversification of options across social-ecological systems and scales. Saito et al. (2018) suggested that a food sharing culture can contribute to enhancing resilience against socio-economic changes and natural disasters. Given rapid and dynamic global change, human well-being is dependent on social-ecological resilience for adaptive capacity and sustainability (Folke et al. 2003). Despite the existence of many conceptual assessment frameworks and models (e.g., Folke 2006; Walker and Salt 2006), localization, downscaling, and customization of resilience assessments to suit a local context is one of the key challenges for evaluating sustainable development, due to gaps and mismatches between theory-driven indicators and local conditions (Yonehara et al. 2017). Rapid expansion of the sharing paradigm is one of the important socio-economic contexts to be considered for resilience and sustainability assessments. Likewise, the concepts and tools for assessing resilience and sustainability should be fed into the sharing paradigm studies. How sharing practices help in ensuring sustainability and creating resilient societies could be a potential future research arena.

\section{Conclusion}

This systematic review of sharing paradigm studies illustrates the state-of-the-art research trend and academic landscape on a wide range of sharing practices. It also highlights gaps in the sharing studies. We demonstrate that the focus of the prevailing literature on sharing is very limited, emphasizing more on, for example, cases of for-profit sharing, sharing of homes and vehicles, and sharing in Western cultures. Our findings also indicate that the contribution of sharing to sustainability and resilience of human societies is yet to be explored and needs the attention of research communities.

Although this study tries to provide a holistic view of the sharing paradigm, our approach has a few limitations. First, certain types of sharing were not fully captured in our samples. For example, a large volume of bike sharing studies tended to use other terms such as 'bike sharing' or 'sharing system' rather than the generally used terms in the sharing paradigm studies. Also, only a few studies on knowledge and information sharing were included in our research since this topic has formed a separate realm, mainly from the perspectives of management or psychology, and often involving keywords of 'knowledge sharing' and 'knowledge exchange' (Wang and Noe 2010). Second, due to the limit of time and resources, we set the boundary of the research as the consumption and distribution of goods and services, excluding public services (e.g., health services), activity sharing or collective experiences (e.g., sports clubs, open-source software), and public actions (politics and use of public space) (McLaren and Agyeman 2015). Further study on outlining shared activities and experiences would provide an additional angle in comprehending the sharing paradigm. Third, our search was limited to scientific papers of peer-reviewed journals. Inclusion of non-academic sources such as websites and reports would be necessary for a better understanding of what and how we are sharing and for finding research gaps.

Despite the limitations above, this study provides a bird'seye view of sharing paradigm studies. This holistic vision on sharing can facilitate discovery of new opportunities for governance of resources (both tangible and intangible), 
leading to 'just sustainabilities' (McLaren and Agyeman 2015). Mapping out the landscape of sharing studies shed a light on the overlooked realms of sharing. Hence, the present study pinpoints the future research scopes on sharing that can significantly contribute towards attaining sustainability and resilience. Beyond sharing businesses, we need to have a closer look at how our nature of sharing is linked to sustainability and resilience of our societies.

Acknowledgement Our heartfelt thanks to Raffaela Kozar for her thorough proofreading of the manuscript. This study was supported by the Environment Research and Technology Development Fund (S-15-1, Japan's Ministry of the Environment) and Grants-in-Aid for Scientific Research (KAKENHI, Japan Society for the Promotion of Science) Number 15KT0027.

\section{Compliance with ethical standards}

Conflict of interest The authors declare no conflict of interest.

\section{Appendix 1}

See Table 1.

\section{Appendix 2}

See Table 2.

Table 2 Shared goods and services by sector

\begin{tabular}{lll}
\hline Category & Sub-category & No. of cases \\
\hline Agriculture & Agricultural products & 3 \\
Education service & Homegarden products & 10 \\
Energy service & Knowledge & 19 \\
Finance & Heat and electricity & 2 \\
& Crowdfunding & 6 \\
Manufactured & Money lending & 11 \\
& Fashion & 26 \\
& Goods & 31 \\
Personal service & Machines and tools & 10 \\
& Vehicles & 44 \\
Real estate & Cooking & 13 \\
& Services and skills & 22 \\
& Farmland & 6 \\
Transportation Service & Living space & 72 \\
Total & Parking lot & 1 \\
\hline & Warehouse & 1 \\
& Work space & 7 \\
& & 40 \\
& & 324 \\
\hline
\end{tabular}

Table 1 The number of publications on the key concepts of sharing paradigm by year

\begin{tabular}{llllllllllll}
\hline Search strings & 2008 & 2009 & 2010 & 2011 & 2012 & 2013 & 2014 & 2015 & 2016 & 2017 & Total \\
\hline Core economy & 2 & 1 & 1 & 0 & 2 & 3 & 3 & 2 & 3 & 3 & 20 \\
Service co-production & 2 & 1 & 0 & 1 & 2 & 3 & 2 & 9 & 8 & 6 & 34 \\
Collaborative lifestyle* & 0 & 0 & 0 & 0 & 0 & 0 & 0 & 1 & 2 & 0 & 3 \\
Collective common* & 3 & 1 & 0 & 1 & 0 & 0 & 2 & 2 & 1 & 0 & 10 \\
Open-sourcing & 3 & 3 & 3 & 1 & 3 & 4 & 1 & 4 & 6 & 5 & 33 \\
Peer production & 12 & 9 & 6 & 11 & 8 & 18 & 18 & 17 & 26 & 16 & 141 \\
Collective economy & 0 & 0 & 0 & 0 & 1 & 1 & 1 & 2 & 3 & 2 & 10 \\
Access economy & 0 & 1 & 0 & 0 & 0 & 0 & 1 & 1 & 0 & 5 & 8 \\
Sharing economy & 0 & 1 & 0 & 1 & 0 & 4 & 10 & 33 & 87 & 187 & 323 \\
Product service system* & 11 & 31 & 31 & 44 & 50 & 51 & 45 & 75 & 67 & 81 & 486 \\
Disownership & 1 & 2 & 0 & 5 & 1 & 7 & 1 & 5 & 5 & 7 & 34 \\
Redistribution market* & 0 & 0 & 0 & 1 & 0 & 0 & 0 & 0 & 0 & 2 & 3 \\
Unconsumption & 0 & 0 & 0 & 0 & 1 & 0 & 0 & 0 & 0 & 0 & 1 \\
Peer-to-peer sharing & 1 & 2 & 1 & 1 & 1 & 2 & 1 & 3 & 4 & 5 & 21 \\
Gift economy & 4 & 5 & 6 & 11 & 5 & 15 & 11 & 11 & 14 & 10 & 92 \\
Total & 39 & 59 & 49 & 77 & 77 & 113 & 98 & 172 & 237 & 354 & 1275 \\
\hline
\end{tabular}

* were used as wildcards in information retrieval 


\section{References}

Ahern J (2011) From fail-safe to safe-to-fail: sustainability and resilience in the new urban world. Landsc Urban Plan 100(4):341-343

Akbar P, Mai R, Hoffmann S (2016) When do materialistic consumers join commercial sharing systems. J Bus Res 69(10):4215-4224

Ala-Mantila S, Ottelin J, Heinonen J, Junnila S (2016) To each their own? The greenhouse gas impacts of intra-household sharing in different urban zones. J Clean Prod 135:356-367

Albinsson PA, Perera BY (2009) From trash to treasure and beyond: the meaning of voluntary disposition. J Consum Behav 8(6):340-353

Albinsson PA, Perera BY (2012) Alternative marketplaces in the 21st century: building community through sharing events. J Consum Behav 11(4):303-315

Aptekar S (2016) Gifts among strangers: the social organization of freecycle giving. Soc Probl 63(2):266-283

Ballus-Armet I, Shaheen SA, Clonts K, Weinzimmer D (2014) Peerto-peer carsharing: exploring public perception and market characteristics in the San Francisco Bay area, California. Transp Res Record 2416(1):27-36

Balnaves M (2012) The Australian finance sector and social media: towards a history of the new banking. Media Int Aust 143(1):132-145

Barnes SJ, Mattsson J (2016) Building tribal communities in the collaborative economy: an innovation framework. Prometheus 34(2):95-113

Belk R (2007) Why not share rather than own? Ann Am Acad Polit Social Sci 611(1):126-140

Belk R (2010) Sharing: Table 1. J Consum Res 36(5):715-734

Belk R (2014) You are what you can access: sharing and collaborative consumption online. J Bus Res 67(8):1595-1600

Berners-Lee M (2011) How bad are bananas?: the carbon footprint of everything. Greystone Books, Berkeley

Boafo YA, Saito O, Jasaw GS, Otsuki K, Takeuchi K (2016) Provisioning ecosystem services-sharing as a coping and adaptation strategy among rural communities in Ghana's semi-arid ecosystem. Ecosyst Serv 19:92-102

Botsman R, Rogers R (2010) What's mine is yours. The rise of collaborative consumption. HarperCollins Publishers, New York

Boyko CT, Clune SJ, Cooper RF, Coulton CJ, Dunn NS, Pollastri S, Leach JM, Bouch CJ, Cavada M, De Laurentiis V, GoodfellowSmith M (2017) How sharing can contribute to more sustainable cities. Sustainability 9(5):701

Bradley K, Pargman D (2017) The sharing economy as the commons of the 21st century. Camb J Regions, Econ Soc 10(2):231-247

Bruggeman D, Dehaene M (2017) Urban questions in the countryside? Urbanization and the collective consumption of electricity in early twentieth-century Belgium. Plan Perspect 32(3):309-332

Bucher E, Fieseler C, Lutz C (2016) What's mine is yours (for a nominal fee)-exploring the spectrum of utilitarian to altruistic motives for Internet-mediated sharing. Comput Hum Behav 62:316-326

Buczynski B (2013) Sharing is good: how to save money, time and resources through collaborative consumption. New Society Publishers, British Columbia

Butenko A (2016) Sharing energy: dealing with regulatory disconnection in Dutch energy law. Eur J Risk Regul 7(4):701-716

Cellucci C, Sivo M Di (2017) Shareable city, regenerated by making. Int J Sustain Dev Plan 12(3):388-394

Chasin F, von Hoffen M, Cramer M, Matzner M (2017) Peer-to-peer sharing and collaborative consumption platforms: a taxonomy and a reproducible analysis. Inf Syst e-Bus Manag 16:1-33

Cheng D (2014) Is sharing really caring? A nuanced introduction to the peer economy. Policy Primer. http://static.opensocietyfoundatio ns.org/misc/future-of-work/the-sharing-economy.pdf. Accessed $24 \mathrm{Feb} 2018$

Cheng M (2016) Current sharing economy media discourse in tourism. Ann Tour Res 60:111-114

Donini A, Forlivesi M, Rota A, Tullini P (2017) Towards collective protections for crowdworkers: Italy, Spain and France in the EU context. Transfer: Eur Rev Labour Res 23(2):207-223

Dredge D, Gyimóthy S (2015) The collaborative economy and tourism: critical perspectives, questionable claims and silenced voices. Tour Recreat Res 40(3):286-302

Fellows NT, Pitfield DE (2000) An economic and operational evaluation of urban car-sharing. Transp Res Part D: Transp Environ $5(1): 1-10$

Folke C (2006) Resilience: the emergence of a perspective for socialecological systems analyses. Glob Environ Change 16:253-267

Folke C, Colding J, Berkes F (2003) Synthesis: building resilience and adaptive capacity in social-ecological systems. In: Berkes F, Colding J, Folke C (eds) Navigating social-ecological systems: building resilience for complesity and change. Cambridge University Press, Cambridge, pp 352-383

Hamari J, Sjoklint M, Ukkonen A (2016) The sharing economy: why people participate in collaborative consumption. J Assoc Inf Sci Technol 67(9):2047-2059

Heylighen F (2017) Towards an intelligent network for matching offer and demand: from the sharing economy to the Global Brain. Technol Forecast Soc Chang 114:74-85

Hollnagel E, Paries J, Woods DD, Leveson N (eds) (2006) Resilience engineering: concepts and recepts. Ashgate Publishing, Aldershot

Huber A (2017) Theorising the dynamics of collaborative consumption practices: a comparison of peer-to-peer accommodation and cohousing. Environ Innov Soc Transit 23:53-69

Ince A (2015) From middle ground to common ground: self-management and spaces of encounter in organic farming networks. Ann Assoc Am Geogr 105(4):824-840

Intergovernmental Panel on Climate Change (IPCC) (2014) Summary for policymakers. In: Climate change 2014: impacts, adaptation, and vulnerability. Part A: global and sectoral aspects, Contribution of Working Group II to the Fifth Assessment Report. Cambridge University Press, Cambridge, UK

John NA (2013) The social logics of sharing. Commun Rev 16(3):113-131

Kamiyama C, Hashimoto S, Kohsaka R, Saito O (2016) Non-market food provisioning services via homegardens and communal sharing in satoyama socio-ecological production landscapes on Japan's Noto peninsula. Ecosyst Serv 17:185-196

Kassan J, Orsi J (2012) The legal landscape of the sharing economy. J Environ Law Litigat 27(1):1-20

Laamanen M, Wahlen S, Campana M (2015) Mobilising collaborative consumption lifestyles: a comparative frame analysis of time banking. J Consumer Stud 39(5):459-467

Lahti VM, Selosmaa J (2013) A fair share: towards a new collaborative economy. Atena

Lampinen A, Huotari KJE, Cheshire C (2015) Challenges to participation in the sharing economy: the case of local online peer-to-peer exchange in a single parents' network. Interaction Design and Architecture

Landreth N, Saito O (2014) An ecosystem services approach to sustainable livelihoods in the homegardens of Kandy, Sri Lanka. Aust Geographer 45(3):355-373

Langley P, Leyshon A (2017) Capitalizing on the crowd: the monetary and financial ecologies of crowdfunding. Environ Plan A 49(5):1019-1039

Luckner N, Fitzpatrick G, Werner K, Subasi Ö (2015) Setting up and running a sharing service: an organisational perspective. IXD\&A 24:63-80 
Manyika J, Lund S, Bughin J, Robinson K, Mischke J, Mahajan D (2016) Independent work: choice, necessity, and the gig economy. McKinsey \& Company

Martin CJ (2016) The sharing economy: a pathway to sustainability or a nightmarish form of neoliberal capitalism? Ecol Econ 121:149-159

McLaren D, Agyeman J (2015) Sharing cities: a case for truly smart and sustainable cities. MIT Press, Cambridge

Novel AS (2014) Is sharing more sustainable? The environmental promises of the sharing economy. Innovat Sustain Dev 139-144

Pedersen ERG, Netter S (2015) Collaborative consumption: business model opportunities and barriers for fashion libraries. J Fashion Market Manag 19(3):258-273

Pettersen L (2017) Sorting things out: a typology of the digital collaborative economy. First Monday 22:8

Pfeffer-Gillett A (2016) When "disruption" collides with accountability: holding ridesharing companies liable for acts of their drivers. Cal L Rev 104:233

Phillips RL, Ormsby R (2016) Industry classification schemes: an analysis and review. J Bus Fin Librarianship 21(1):1-25

Plieninger T, Kohsaka R, Bieling C, Hashimoto S, Kamiyama C, Kizos T, Penker M, Kieninger P, Shaw BJ, Sioen GB, Yoshida Y (2018) Fostering biocultural diversity in landscapes through place-based food networks: a "solution scan" of European and Japanese models. Sustain Sci 13(1):219-233

Preston F (2012) A global redesign? shaping the circular economy, energy, environment and resource governance. https://s3.amazo naws.com/academia.edu.documents/32547802/A_global_rede sign_-_shaping_the_circular_economy.pdf?AWSAccessKeyI $\mathrm{d}=$ AKIAIWOWYYGZ2Y53UL3A\&Expires $=1534250859 \&$ Signature $=$ YPQPPEbRzh9FYgM2k0D4V6tphYY\%3D\&respo nse-content-disposition $=$ inline $\% 3 \mathrm{~B} \% 20$ filename\%3Dbriefing paper_A_Global_Redesign_Shaping.pdf

Price JA (1975) Sharing: the integration of intimate economies. Anthropologica 3-27

PricewaterhouseCoopers (PwC) (2015) The sharing economy. Consumer Intelligence Series

Ravenelle AJ (2017) Sharing economy workers: selling, not sharing. Camb J Regions, Econ Soc 10(2):281-295

UN General Assembly resolution (2015) 70/1 on "transforming our world: the 2030 agenda for Sustainable Development'” adopted on 25 September 2015, paragraph 72

Retamal M (2017) Product-service systems in Southeast Asia: business practices and factors influencing environmental sustainability. J Clean Prod 143:894-903

Rifkin J (2001) The age of access: the new culture of hypercapitalism. Penguin
Roos D, Hahn R (2017) Does shared consumption affect consumers' values, attitudes, and norms? a panel study. J Bus Res 77:113-123

Saito O, Havas J, Shirai K, Kurisu K, Aramaki T, Hanaki K (2015) Non-market food provisioning services in Hachijo Island, Japan and their implications toward building a resilient island. J Jpn Soc Civ Eng, ser G Environ Res 71(6):349-357

Saito O, Kamiyama C, Hashimoto S (2018) Non-market food provision and sharing in Japan's socio-ecological production landscapes. Sustainability 10:213. https://doi.org/10.3390/su10010213

Schor JB (2017) Does the sharing economy increase inequality within the eighty percent?: findings from a qualitative study of platform providers. Camb J Regions, Econ Soc 10(2):263-279

Shaheen S, Chan N (2016) Mobility and the sharing economy: potential to facilitate the first-and last-mile public transit connections. Built Environment 42(4):573-588

Takeuchi K, Saito O, Lahoti S, Gondor D (2017) Growing up: 10 years of publishing sustainability science research. Sustain Sci 12:849-854

Thebault-Spieker J, Terveen L, Hecht B (2017) Toward a geographic understanding of the sharing economy: systemic biases in UberX and TaskRabbit. ACM Trans Comput Hum Inter (TOCHI) 24(3):21

Todolí-Signes A (2017) The 'gig economy': employee, self-employed or the need for a special employment regulation? Transfer: Eur Rev Lab Res 23(2):193-205

Tolkach D, Chon KK, Xiao H (2016) Asia Pacific tourism trends: is the future ours to see? Asia Pac J Tour Res 21(10):1071-1084

Tussyadiah IP (2015) An exploratory study on drivers and deterrents of collaborative consumption in travel. Information and communication technologies in tourism 2015. Springer, Cham, pp 817-830

Tussyadiah IP (2016) Factors of satisfaction and intention to use peerto-peer accommodation. Int J Hosp Manag 55:70-80

Wahyuningtyas SY (2016) The online transportation network in Indonesia: a pendulum between the sharing economy and ex ante regulation. Compet Regul Netw Ind 17(3-4):260-280

Walker BH, Salt D (2006) Resilience thinking: sustaining ecosystems and people in a changing world. Island Press, Washington, DC

Wang S, Noe RA (2010) Knowledge sharing: a review and directions for future research. Hum Resour Manag Rev 20(2):115-131

Wittel A (2011) Qualities of sharing and their transformations in the digital age. Int Rev Inf Ethics 15(9):3-8

Xu L, Marinova D, Guo X (2015) Resilience thinking: a renewed system approach for sustainability science. Sustain Sci 10(1):123-138

Yonehara A, Saito O, Hayashi K, Nagao M, Yanagisawa R, Matsuyama K (2017) The role of evaluation for achieving the SDGs. Sustain Sci 12:969-973 